\title{
Design and Simulation Analysis of Transplanter's Planting Mechanism
}

\author{
Fa Liu, Jianping Hu, Yingsa Huang, Xiuping Shao, and Wenqin Ding
}

Key Laboratory of Modern Agricultural Equipment and Technology, Ministry of Education\&Jiangsu Province, Jiangsu University, Zhenjiang 212013, China

liufa1020@126.com

\begin{abstract}
A new-style transplanter's planting mechanism was designed, which was composed of Planetary Gear, Planetary Carrier, Connecting rod, Groove cam and Planting arm. Built the kinematics model and determined the main parameters which influenced the Plant-arm's locus by analyzing of the Kinematic model. Created the 3D Model in PRO/E and imported it into the Kinematics simulation software ADAMS, analyzing Groove-cam's offset angle, Connecting-rod's length and its impact on the Plant-arm's kinematics locus. The effect laws of the structural parameters on the Plant-arm's locus were obtained through analyzing the Plant-arm's locus, which got by changing the groove cam's horizontal offset angle ranging from $0^{\circ}$ to $20^{\circ}$, the sum of Connecting-rod's length ranging from $130 \mathrm{~mm}$ to $150 \mathrm{~mm}$, and the subtract of Connecting-rod's length ranging from $15 \mathrm{~mm}$ to $25 \mathrm{~mm}$. The analysis results are of theoretical significance to the dimension synthesis and optimization design.
\end{abstract}

Keywords: Transplanter, planting mechanism, ADAMS, Groove cam, Plant-arm's kinematics locus.

\section{Introduction}

Raise seedling and transplant can increase crop production in every unit area, and make upgrowth ahead of time, which can withstand gale, harmful rain, low temperature, and other nature disaster. Besides, it also saving seed. Seeds are usually grown under the film by farmer in many place, because it is useful to improve the soil temperature, keep moisture and restrain weeds.

The nacelle-type and dibble-type transplanting mechanism are good mechanism for transplanting film, but they are not convenient and safe to directly drop seedling and they are easy to leave out seedling when the machine are operated and their work efficient are low when seedling are transplanted over the larger areas. Now a simple and credible type of transplanting mechanism was designed, which was easy and convient to be operated and adjusted. the efficiency of the machine was much more greatly improved. There was less seedling to leave out in work progress. The three dimension model of the transplanting mechanism was establish in pro/e software. The relationship between the planting arm's locus and structural parameters was analyzed by the mechanical simulation software ADAMS in this paper. 


\section{Kinematic Analysis of the Planting Mechanism}

\subsection{Structure and Working Principle of Planting Mechanism}

A transplanter's planting mechanism was shown in Figure 1, which was composed of planetary gear, planetary carrier, link, groove cam and planting arm. The numbers of sun-wheel's teeth was twice times that of the planetary gear's teeth. The cam groove was divided into two parts and a angle-off between the two part. Planting arm, fixed on the connecting rod 2 , moved with the connecting rod 2.

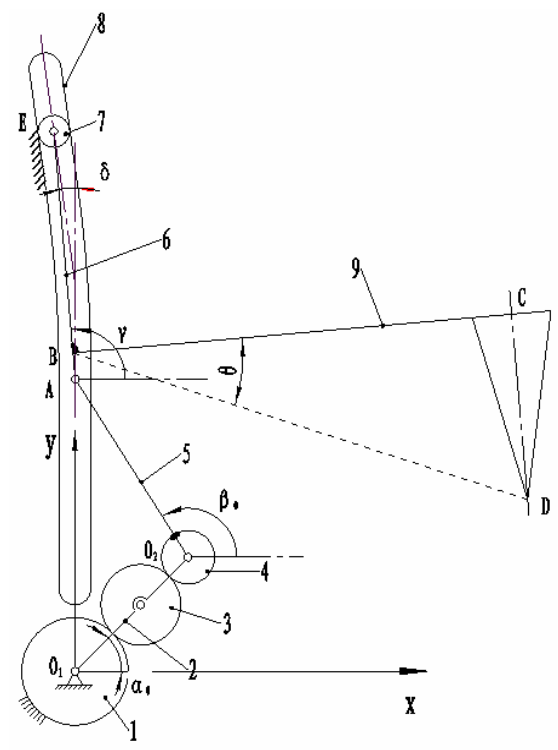

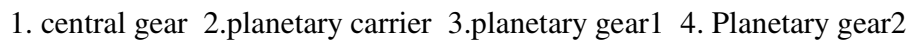
5.connecting rod1 6.connecting rod2 7.roller 8. Groove cam 9.planting arm

Fig. 1. Planting mechanism structural chart

\subsection{Transplanter's Planting Mechanism Kinematics Equations}

The initial position of planting bodies was shown in Figure 1. The Cartesian named $\mathrm{xO}_{1} \mathrm{y}$ established as shown in fig.1. The Coordinate equation of the planetary gear's center $\mathrm{O}_{2}$ is:

$$
\left\{\begin{array}{l}
x_{O_{2}}=l_{1} \cos \left(\alpha_{0}+\omega t\right) \\
\mathrm{y}_{O_{2}}=l_{1} \sin \left(\alpha_{0}+\omega t\right)
\end{array}\right.
$$


The Coordinate equation of the connecting rod's endpoint A is:

$$
\left\{\begin{array}{l}
x_{A}=x_{O_{2}}+l_{2} \cos \left(\beta_{0}+\omega t\right) \\
y_{A}=y_{O_{2}}+l_{2} \sin \left(\beta_{0}+\omega t\right)
\end{array}\right.
$$

The Coordinate equation of planting arm's endpoint B is:

$$
\left\{\begin{array}{l}
x_{B}=x_{A}+l_{3} \cos \gamma \\
y_{B}=y_{A}+l_{3} \sin \gamma
\end{array}\right.
$$

The Coordinate equation of planting arm's endpoint D is:

$$
\left\{\begin{array}{l}
x_{D}=x_{\mathrm{B}}+\rho \cos \left(\theta+\frac{\pi}{2}-\gamma\right) \\
y_{D}=y_{B}-\rho \sin \left(\theta+\frac{\pi}{2}-\gamma\right)
\end{array}\right.
$$

The rate equation of the planetary gear's center $\mathrm{O}_{2}$ is:

$$
\left\{\begin{array}{l}
v_{x_{O_{2}}}=\omega l_{1} \sin \left(\alpha_{0}+\omega t\right) \\
v_{y_{o_{2}}}=\omega l_{1} \cos \left(\alpha_{0}+\omega t\right)
\end{array}\right.
$$

The endpoint $\mathrm{A}$ of the connecting rod 1 rate equation is:

$$
\left\{\begin{array}{l}
v_{x_{A}}=v_{x_{O_{2}}}+\omega l_{2} \sin \left(\beta_{0}+\omega t\right) \\
v_{y_{A}}=v_{x_{O_{2}}}+\omega l_{2} \cos \left(\beta_{0}+\omega t\right)
\end{array}\right.
$$

The rate equation of the planting arm's endpoint B is:

$$
\left\{\begin{array}{l}
v_{x_{B}}=v_{x_{A}}+\omega_{2} l_{3} \sin \gamma \\
v_{y_{B}}=v_{x_{A}}+\omega_{2} l_{3} \cos \gamma
\end{array}\right.
$$

The rate equation of the planting arm's endpoint $\mathrm{D}$ is:

$$
\left\{\begin{array}{l}
v_{x_{D}}=v_{x_{B}}-\omega_{2} \rho \sin \left(\theta+\frac{\pi}{2}-\gamma\right) \\
v_{y_{D}}=v_{x_{D}}+\omega_{2} \rho \cos \left(\theta+\frac{\pi}{2}-\gamma\right)
\end{array}\right.
$$


$\omega_{2}=\gamma$

$\alpha_{0}$ - the initial angle between the planetary carrier and the horizontal

$\beta_{0}$ _ the initial angle between connecting rod 1 and the horizontal

$\gamma$ - the angle between connecting rod 2 and the horizontal

$\theta-\angle \mathrm{CBD}$

$l_{1}$ the length of the planet carrier

$l_{2}$ _the length of the connecting rod 1

$l_{3}$ _the length of the connecting rod 3

$\omega$ - the angular velocity of the planet carrier

\section{Virtual Prototype Model of the Planting Mechanism}

The planting mechanism's three-dimensional model was established and assembled in the pro/e and then transmited it into the mechanical simulation software Adams. The Planting mechanism's Virtual Prototype Model was established in the mechanical simulation software Adams as in Fig.2.

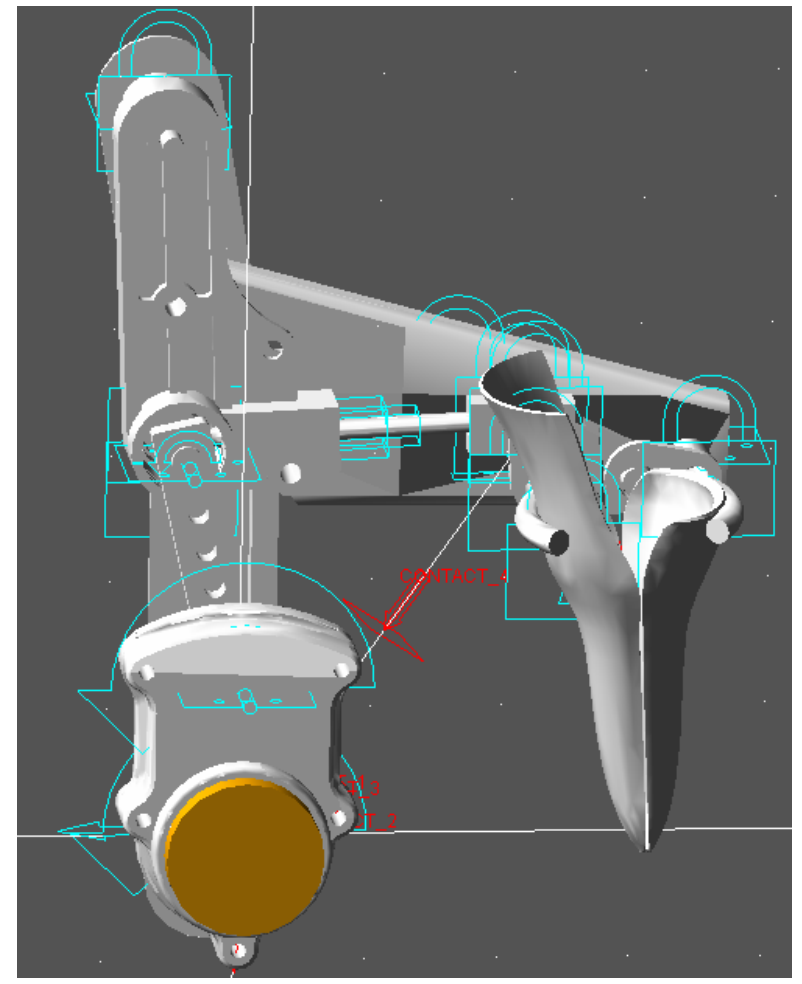

Fig. 2. The Planting mechanism's Virtual Prototype Model 


\section{Kinematics Simulation}

\subsection{Planting Mechanism's Simulation in Different Structural Parameters}

The shape of the planting arm's locus was the chief factor to effect the function of the transplanter. The groove cam's horizontal offset angle, the sum of Connecting-rod length and the subtract of Connecting-rod length were the main factors to effect the Plant-arm's locus by analyzing the transplanter's planting mechanism kinematics equations. So we built the Virtual Prototype Model of the Planting mechanism in the different structural parameters of the groove cam's horizontal offset angle, the sum of Connecting-rod length and the subtract of Connecting-rod length. The Planting arm's locus were got by the different Virtual Prototype Model's simulation as in Fig.3, Fig.4 and Fig.5. Structural parameter values in Table 1.

Table 1. Structural parameter

\begin{tabular}{|c|c|c|c|}
\hline & $\begin{array}{c}\text { A } \\
\text { (groove cam's } \\
\text { horizontal offset } \\
\text { angle) }\end{array}$ & $\begin{array}{c}\text { B } \\
\text { (sum of } \\
\text { Connecting-rod length) }\end{array}$ & $\begin{array}{c}\text { C } \\
\text { (subtract of } \\
\text { Connecting-rod length) }\end{array}$ \\
\hline 1 & $0^{\circ}$ & $0 \mathrm{~mm}$ & $120 \mathrm{~mm}$ \\
\hline 2 & $5^{\circ}$ & $10 \mathrm{~mm}$ & $130 \mathrm{~mm}$ \\
\hline 3 & $10^{\circ}$ & $20 \mathrm{~mm}$ & $140 \mathrm{~mm}$ \\
\hline 4 & $15^{\circ}$ & $30 \mathrm{~mm}$ & $150 \mathrm{~mm}$ \\
\hline 5 & $20^{\circ}$ & $40 \mathrm{~mm}$ & $160 \mathrm{~mm}$ \\
\hline
\end{tabular}

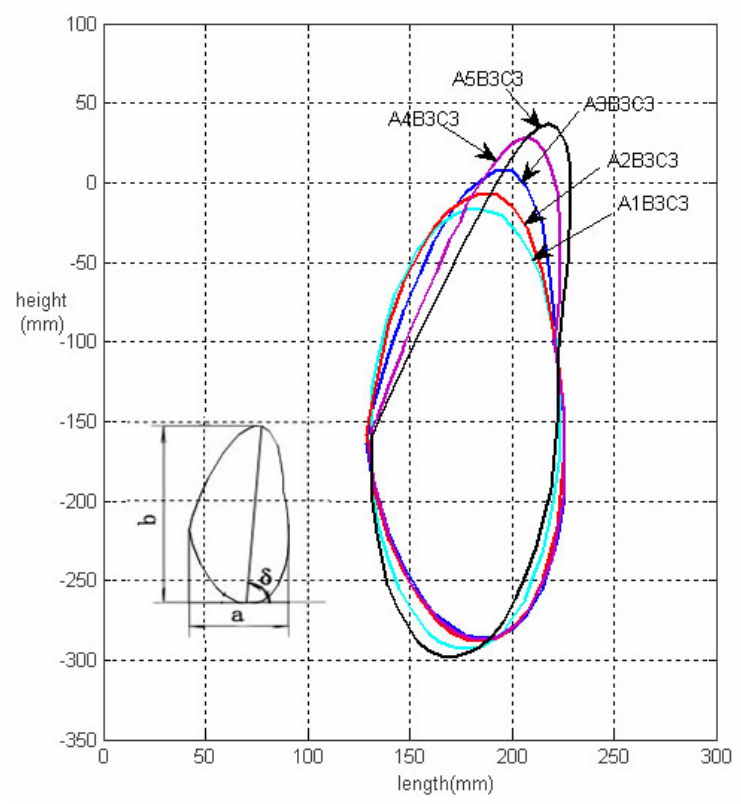

Fig. 3. Planting arm's locus in different groove cam's horizontal offset angle 
Fig 3, Fig4 and Fig 5 is the planting arm's locus in different structural parameters respectively.

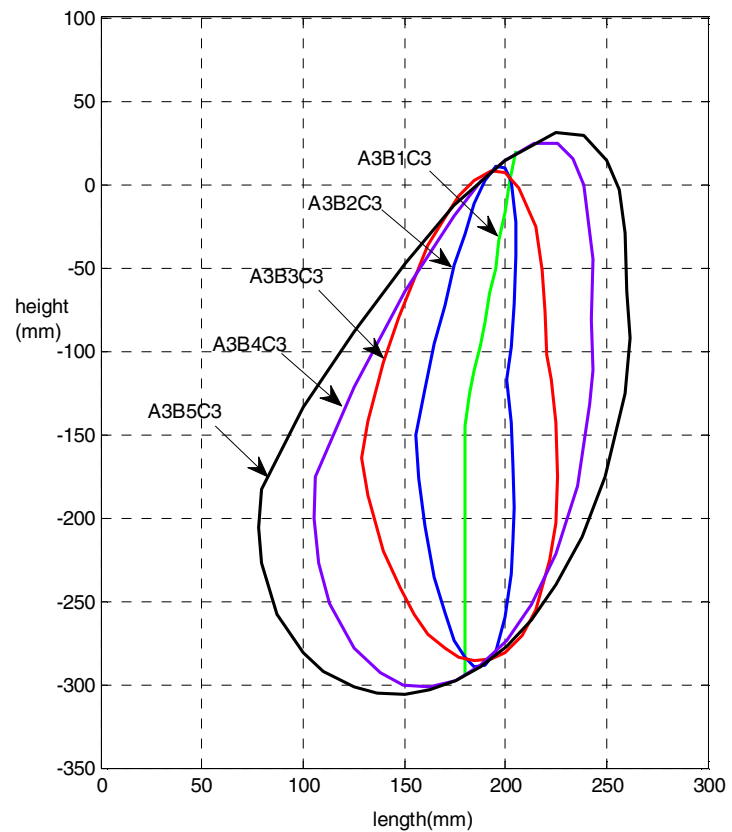

Fig. 4. Planting arm's locus in different subtract of Connecting-rod length

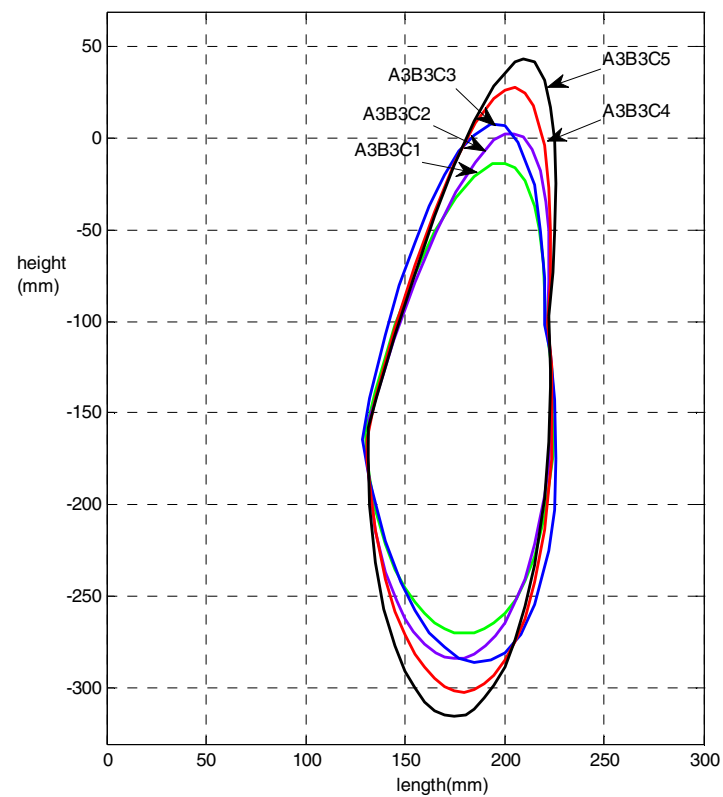

Fig. 5. Planting arm's locus in different sum of Connecting-rod length 


\subsection{The Simulation Results of Planting Mechanism Were Analyzed in Different Structural Parameters}

The shape of the planting arm's locus was determined by the width of planting arm's locus, the height and the deflection angle. So we selected the width of planting arm's locus, the height and the deflection angle as the evaluation criteria of planting arm's locus in this paper. The locus of the planting arm's was got by the simulation of the planting mechanism's virtual prototype model was in different structural parameters. Shown in Table 2.

a-the width of planting arm's locus. The planting distance was influenced by the value of a.

b-the height of planting arm's locus. The Planting Depth was influenced by the value of $b$.

c-the deflection angle of planting arm's locus, It was the angle between the horizontal and the line connecting the lowest point and the highest point of the locus. The stability of catching seedling were influenced by the value of $c$.

Table 2. Simulation results analysis

\begin{tabular}{|c|c|c|c|c|}
\hline \multirow{2}{*}{$\begin{array}{l}\text { Structural } \\
\text { parameters }\end{array}$} & \multirow{2}{*}{$\begin{array}{l}\text { Results } \\
\text { Fig. }\end{array}$} & \multicolumn{3}{|c|}{ Indicator value } \\
\hline & & Width(a) & Length(b) & Declination $(\delta)$ \\
\hline A1B3C3 & \multirow{5}{*}{ Fig. 3} & 93 & 276 & $0^{\circ}$ \\
\hline A2B3C3 & & 97 & 281 & $0.6^{\circ}$ \\
\hline A3B3C3 & & 97 & 292 & $3^{\circ}$ \\
\hline A4B3C3 & & 96 & 315 & $4.4^{\circ}$ \\
\hline А5В3C3 & & 98 & 335 & $7.9^{\circ}$ \\
\hline A3B1C3 & \multirow{5}{*}{ Fig. 4} & 25 & 315 & $4.5^{\circ}$ \\
\hline A3B2C3 & & 49 & 300 & $1.9^{\circ}$ \\
\hline A3B3C3 & & 97 & 292 & $3^{\circ}$ \\
\hline A3B4C3 & & 138 & 326 & $9^{\circ}$ \\
\hline A3B5C3 & & 183 & 336 & $12^{\circ}$ \\
\hline A3B3C1 & \multirow{5}{*}{ Fig. 5} & 94 & 256 & $4.5^{\circ}$ \\
\hline A3B3C2 & & 93 & 286 & $5.8^{\circ}$ \\
\hline A3B3C3 & & 97 & 292 & $3^{\circ}$ \\
\hline A3B3C4 & & 93 & 330 & $4.4^{\circ}$ \\
\hline A3B3C5 & & 94 & 360 & $5.6^{\circ}$ \\
\hline
\end{tabular}

As is shown in Table 2, Fig. 3 shows a set of curves of a width of about $97 \mathrm{~mm}$, a height ranging from $276 \mathrm{~mm}$ to $335 \mathrm{~mm}$ and a declination angle ranging from $0^{\circ}$ to $7.9^{\circ}$. Fig. 4 shows a set of curves of a width ranging from $25 \mathrm{~mm}$ to $183 \mathrm{~mm}$, a height ranging from $292 \mathrm{~mm}$ to $336 \mathrm{~mm}$ and a declination angle ranging from $1.9^{\circ}$ to $16^{\circ}$. Fig. 5 shows a set of curves of a width of about $94 \mathrm{~mm}$, a height ranging from $256 \mathrm{~mm}$ to $360 \mathrm{~mm}$ and a declination angle ranging from $3^{\circ}$ to $5.6^{\circ}$. 


\section{Conclusion}

(1) The width of planting arm's locus depends on the subtract of Connecting-rod length. With the subtract of Connecting-rod length increasing, the width of planting arm's locus became wider and wider.

(2) The height of planting arm's locus depends on the sum of Connecting-rod length, the subtract of Connecting-rod length and the groove cam's horizontal offset angle. With the sum of Connecting-rod length, the subtract of Connecting-rod length and the groove cam's horizontal offset angle increasing, the height of planting arm's locus became larger and larger.

(3) The deflection angle of planting arm's locus depends on the groove cam's horizontal offset angle and the subtract of Connecting-rod length. With the groove cam's horizontal offset angle and the subtract of Connecting-rod length increasing, the deflection angle of planting arm's locus width of planting arm's locus became wider and wider.

\section{Acknowledgements}

This work was financially supported by the three agricultural machinery project of Jiangsu Province for 2008.

\section{References}

[1] Wang, W., Dou, W., Wang, C.: Parameter Analysis of the planting Process of 2ZT-2 Beet Transplanter. Transactions of the Chinese Society for Agricultural Machinery 40(1) (2009)

[2] Li, Q., Wang, Z.: Main structure parameter and analysison planting apparatus with twin conveyer belt. Transactions of the Chinese Society for Agricultural Machinery 28(4), 46-49 (1997)

[3] Dong, F., Geng, D., Wang, Z.: Study on block seedling transplanter with belt feeding mechanism. Transactions of the Chinese Society for Agricultural Machinery 31(2), 42-45 (2000)

[4] Li, Q., Lu, S., Li, L.: Experimental study on a slideway parting-bowl-wheel transplanter. Transactions of the Chinese Society for Agricultural Machinery 32(2), 30-33 (2001) (in Chinese)

[5] Feng, J., Qin, G., Song, W., et al.: The kinematic analysis and design criteria of the dibble-type transplanter. Transactionsof the Chinese Society for Agricultural Machinery 33(5), 48-50 (2002)

[6] Zhou, D., Sun, Y., Cheng, L.: Design and analysis of a supporting-seedling mechanism with cam and combined rocker. Transactionsof the Chinese Society for Agricultural Machinery 34(5), 58-60 (2003)

[7] Yu, G., Zhao, F., Wu, C., et al.: Analysis of kinematic property of separating-planting mechanism with planetary gears. Transactions of the Chinese Society for Agricultural Machinery 35(6), 55-57 (2004) (in Chinese)

[8] Li, Y., Xu, L., Chen, H.: Improved design of spade arm in 4YS-600 tree transplanter. Transactions of the CSAE 25(3), 60-63 (2009) (in Chinese and English abstract) 